\title{
CATÁLOGO ONLINE EM BIBLIOTECAS PÚBLICAS MUNICIPAIS DO ESTADO DO PARANÁ
}

\section{ONLINE CATALOG IN MUNICIPAL PUBLIC LIBRARIES IN THE STATE OF PARANÁ}

\author{
Marcos Moraesa \\ Zoraide Aparecida Gasparinib \\ Leda Maria Araújoc
}

\begin{abstract}
RESUMO
Introdução: No contexto das bibliotecas, sejam públicas ou de outros tipos, o catálogo sempre desempenhou importante papel nas tarefas de localizar, descrever e inventariar os conteúdos informacionais. Atualmente, com as amplas possibilidades de uso dos Online Public Access Catalogs, ou simplesmente OPACs, as bibliotecas podem utilizar essa ferramenta, não mais somente para recuperar, descrever ou inventariar os acervos, mas também como importante canal de divulgação e de comunicação com usuários reais e potenciais das bibliotecas. Entretanto, o contexto das bibliotecas públicas brasileiras impõe barreiras à adoção dos OPACs, visto que os custos de compra e manutenção de softwares voltados para essa finalidade não são considerados como prioritários para muitas dessas instituições. Objetivo: Esta pesquisa tem como objetivo investigar a situação das bibliotecas públicas municipais das maiores cidades do estado do Paraná, no que se refere a adoção ou não dos OPACs, observando ainda, quando o caso, quais softwares e funcionalidades existentes nos OPACs. Metodologia: Levando-se em consideração os objetivos propostos para esse trabalho, trata-se de uma pesquisa do tipo exploratória com abordagem tanto quantitativa quanto qualitativa. Resultados: Percebeu-se que metade das 20 cidades pesquisadas, ou seja, 10 cidades mantêm OPACs, ao passo que em outras 10 cidades não foi percebida a existência dessa ferramenta. Conclusões: Destaca-se de maneira positiva, o esforço conjunto liderado pela Biblioteca Pública do Paraná, que é um órgão estadual, no que se refere a oportunizar que algumas cidades paranaenses possam utilizar o software Pergamun para prover acesso público online aos catálogos de suas bibliotecas. Da mesma maneira que Londrina, Araucária, Arapongas e Cambé, cujas bibliotecas públicas municipais utilizam diferentes softwares para administrar seus OPACs. Todavia, a ausência dos

\footnotetext{
a Doutor em Ciência da Informação pela Universidade Estadual Paulista Julio de Mesquita Filho (PPGCI-UNESP). Bibliotecário do Sistema de Bibliotecas Públicas Municipais de Londrina. Email: marcosmoraes@uel.br

b Especialista em Gestão de Bibliotecas Universitárias pela Universidade Estadual de Londrina (UEL). Bibliotecária do Sistema de Bibliotecas Públicas Municipais de Londrina. E-mail: gasparini7@gmail.com

c Doutoranda em Ciência da Informação pela Universidade Estadual Paulista "Julio de Mesquita Filho" (UNESP/Marília). Diretora do Sistema de Bibliotecas Públicas Municipais de Londrina. Email: le-araujo@hotmail.com
} 
OPACs em bibliotecas públicas de 10 das maiores cidades do Paraná, dentre elas a capital Curitiba, indica que há muito que avançar no sentido de oportunizar o uso dessa importante ferramenta.

Descritores: Catálogo online. Online Public Access Catalogs. OPAC. Biblioteca Pública.

\section{INTRODUÇÃO}

As bibliotecas têm uma longa e importante história junto à humanidade. Assumiram ao longo dos tempos, papéis fundamentais, tais como o de reunir, controlar, compartilhar e preservar os registros do conhecimento humano, em diversas formas e fontes. Desde o princípio dessas instituições, uma importante ferramenta apoiou as diversas atividades das bibliotecas; trata-se do catálogo, instrumento primordial de toda biblioteca, tanto para os bibliotecários, profissionais que têm a atribuição de produzir os catálogos, de acordo com normas e padrões amplamente difundidos, como para os usuários, que utilizam o catálogo como principal ferramenta de recuperação de informação em bibliotecas e outras unidades de informação.

Tendo em vista tamanha importância dos catálogos para as bibliotecas, a construção, uso, os aspectos teóricos e práticos concernentes aos catálogos sempre foram objetos de estudo por parte da comunidade de pesquisadores das áreas da Biblioteconomia, Documentação e Ciência da Informação.

Nas últimas décadas, com o surgimento dos catálogos online ou como são mais conhecidos, Online Public Access Catalogs, os OPACs, viu-se um incremento nas pesquisas voltadas para a informatização dos sistemas e dos catálogos, dos modelos de comportamento de busca e na interação do usuário com o sistema. Visto que as tecnologias que dão suporte ao funcionamento dos OPACs encontram-se em constante evolução, as pesquisas voltadas a esse tema não se esgotam, pelo contrário, são constantemente e amplamente necessárias. Desse modo, esta pesquisa buscou conhecer a realidade das bibliotecas públicas municipais das maiores cidades do Paraná no que se refere ao uso dos OPACs em suas bibliotecas.

Trata-se de um estudo exploratório, com abordagem quantitativa e qualitativa que buscou reunir e analisar os dados disponibilizados pelos sites de 
internet de cada biblioteca pública municipal das 20 maiores cidades do Paraná, sendo em alguns casos necessário recorrer ao uso do endereço eletrônico, como forma de comunicação para obtenção dos dados pertinentes a pesquisa.

\section{BIBLIOTECAS, CATÁLOGOS E OPACS}

Uma das funções primordiais de uma biblioteca é promover o acesso da informação aos usuários. Nesse sentido, o catálogo sempre desempenhou um importante papel ao proporcionar maneiras de representar, inventariar, organizar e localizar os registros informacionais das coleções de bibliotecas. Embora existam, no contexto das bibliotecas, outras ferramentas que possibilitam a organização, armazenamento e recuperação da informação, o catálogo é o mais importante deles. Nessa mesma perspectiva, Mey (1987, p. 18), afirma que "o catálogo é o mais importante porque é mais permanente, mais exaustivo e mais preciso".

Ao arrolar os principais objetivos dos catálogos, Souza (2012, p. 3), afirma que:

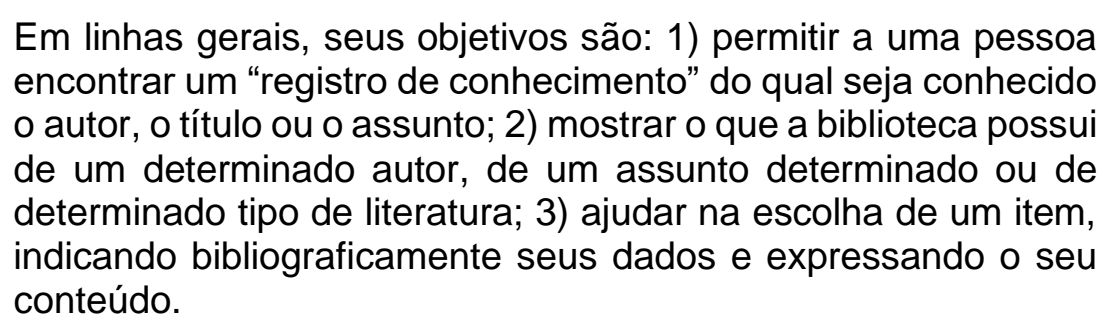

Já para Fiuza (1987), a respeito das funções primordiais de um catálogo de bibliotecas, afirma que tal ferramenta exercia diversas funções, dentre elas três principais. A de localizar, pois tem como objetivo indicar a existência, ou não, de algum item dentro de uma coleção, bem como a sua localização; a de descrever, posto que os catálogos disponibilizam as principais informações descritivas de cada um dos itens de seus acervos; e por fim, a função instrutiva, pois reúnem as obras de um autor, de um assunto e assuntos correlatos. No mesmo sentido de Fiuza (1987), Arruda e Chagas (2002), argumenta que os catálogos são os principais responsáveis por difundir o conteúdo das coleções, pois o catálogo é um conjunto de fichas que determina a existência ou não de certa obra conhecida pelo autor, título, a sua localização e o que possui a biblioteca sobre um determinado assunto e onde pode ser encontrado. 
Da mesma maneira, Leitão e Calixto (2012, p. 38), concordam que os catálogos, no contexto específico das bibliotecas públicas:

Apesar de não constituir a única forma de aceder às coleções tendo em conta o tradicional serviço de livre acesso às coleções, - catálogo desempenha funções cruciais nas bibliotecas públicas. Em primeiro lugar, como instrumento de recuperação da informação bibliográfica e de acesso às coleções, razão maior da sua existência como serviço para o utilizador. Em segundo lugar, como ferramenta que apoia processos de gestão da Biblioteca, nomeadamente, gestão de coleções, assumindo neste contexto o seu primeiro e mais tradicional papel de inventário.

Não se pode negar a importância fundamental do catálogo para muitos processos de gestão de coleções e bibliotecas. Esse papel fundamental não foi perdido com a evolução tecnológica ocorrida nos últimos anos, mas modificouse e ganhou novos contornos, funções e possibilidades.

A evolução das tecnologias de informação e comunicação (TIC) proporcionaram novas formas de trabalho e interação entre bibliotecas, bibliotecários e usuários. Embora parte da sociedade seja categórica ao afirmar que as tecnologias afastaram usuários e bibliotecas, sabe-se que não é esse 0 contexto real. Bibliotecas e bibliotecários, com o uso das tecnologias, foram estimulados a adotarem novas maneiras de trabalho, novas estratégias de organização e compartilhamento da informação, seja em ambientes virtuais, como nas bibliotecas digitais, ou mesmo em ambientes físicos, ou seja, nas bibliotecas tradicionais. É justamente nesse contexto que o catálogo passou por transformações, deixando de ser uma ferramenta administrativa, com finalidade apenas de inventariar as coleções, e tornou-se, para além de uma ferramenta administrativa, um instrumento primordial para mediar as relações de usuários e bibliotecas, quebrando as barreiras físicas impostas pelo âmbito das bibliotecas tradicionais, e levando conteúdos, acervos e coleções além das paredes das bibliotecas (SOUZA, 2012).

Formalmente, os OPACs surgiram nos Estados Unidos, em meados dos anos de 1960. A Biblioteca do Congresso dos Estados Unidos foi a responsável pela criação do formato MARC, que possibilitou a leitura de registros bibliográficos por meio de computadores, oportunizando anos mais tarde 0 surgimento de catálogos eletrônicos, que puderam prover acesso remoto aos 
dados bibliográficos de coleções de bibliotecas ao redor do mundo.

No campo da Biblioteconomia e Ciência da Informação não há consenso acerca do termo ideal a respeito dos catálogos eletrônicos. Diversos autores nomeiam tais ferramentas sob diversas formas, dentre as mais encontradas na literatura especializada na área estão: catálogo eletrônico (electronic catalogs), catálogo online (online catalogs), catálogos de computador (computer catalogs), catálogos de fichas automatizados (automated card catalogs), catálogos de acesso de cliente (patron access catalogs), ou catálogo em linha de acesso público (online public access catalogs), sendo este último o mais adotado, inclusive pela já conhecida sigla de OPACS. (HILDRETH, 1985 apud OLIVEIRA, 2008). Por esse motivo, ou seja, por ser o termo mais percebido na literatura especializada, inclusive no Brasil, optamos por utilizar nesta pesquisa o termo OPAC.

Para Balby (2002, p. 4), os Online Public Access Catalogs, ou simplesmente OPACs são "interfaces a bases de dados que permitem aos usuários (pessoas e instituições) a realização de buscas." Ainda que seja uma definição bastante difundida, em tempos atuais os OPACs, além de permitir a realização de buscas remotas pelos usuários, possibilitam maneiras diversas de divulgação das coleções e serviços das bibliotecas, além de agilizar processos de comunicação e interação entre o público, bibliotecas e bibliotecários.

Suaiden (2000), reflete que o surgimento e a popularização das tecnologias impactaram de diversas maneiras nos serviços bibliotecários. Como já foi anteriormente sinalizado, bibliotecas, bibliotecários e usuários mudaram suas relações. Para o autor, o usuário passou a ser mais independente e crítico, além de ser consciente da existência de diversas outras fontes de informação diferentes da tradicional biblioteca. Nesse novo contexto, os OPACs se modificam, integrando novas tecnologias, tornando sua construção dinâmica e ágil, e por esses motivos, a realização de pesquisas acerca dos catálogos online sempre são necessárias.

\section{PERCURSO METOdOLÓGICO}

Levando-se em consideração os objetivos propostos para esse trabalho, 
trata-se de uma pesquisa do tipo exploratória com abordagem tanto quantitativa quanto qualitativa. Quantitativa, pois pretendeu-se com os resultados, quantificar as cidades paranaenses, com mais de 100 mil habitantes possuem bibliotecas públicas que oferecem o serviço de OPAC aos seus usuários. Já o delineamento qualitativo surge do objetivo de compreender e discutir a respeito da importância do OPAC para as bibliotecas públicas municipais paranaenses, além de refletir a respeito da ausência desse serviço.

Optou-se por restringir a pesquisa somente a bibliotecas municipais de cidades do estado do Paraná cuja população fosse maior do que $100 \mathrm{mil}$ habitantes. A escolha deu-se por entender que a possibilidade de encontrar bibliotecas com OPACs é muito maior em cidades médias ou grandes, visto que essas podem dispor de uma melhor infraestrutura no que se refere a equipamentos culturais ou de educação. Assim, foram identificadas 20 cidades paranaenses com mais de 100 mil habitantes, conforme arroladas no Quadro 1.

Quadro 1 - Cidades do estado do Paraná com mais de 100 mil habitantes

\begin{tabular}{|c|c|c|c|}
\hline Cidade & População & Cidade & População \\
\hline Curitiba & 1917185 & Araucária & 141410 \\
\hline Londrina & 563943 & Toledo & 138572 \\
\hline Maringá & 417010 & Apucarana & 133726 \\
\hline Ponta Grossa & 348043 & Pinhais & 130789 \\
\hline Cascavel & 324476 & Campo Largo & 130091 \\
\hline $\begin{array}{c}\text { São José dos } \\
\text { Pinhais }\end{array}$ & 317476 & Arapongas & 121198 \\
\hline Foz do Iguaçu & 258823 & Almirante & 117168 \\
\hline Colombo & 240840 & Piraquara & 111052 \\
\hline Guarapuava & 180334 & Umuarama & 110590 \\
\hline Paranaguá & 153666 & Cambé & 105704 \\
\hline
\end{tabular}

Fonte: Instituto Brasileiro de Geografia e Estatística (2018) 
Após identificar as 20 cidades procedeu-se com a coleta dos dados, preferencialmente visitando o site das bibliotecas municipais ou ainda buscando contato com os responsáveis pelas bibliotecas por meio do correio eletrônico. Para fins dessa coleta, via site ou e-mail, foi utilizado o Guia de Bibliotecas Públicas Municipais do Paraná, mantido pela Biblioteca Pública do Paraná (2018b). Os dados referentes ao uso ou não uso dos OPACs, aos softwares utilizados (quando fosse o caso) e as funcionalidades do OPAC, foram sistematizados em planilha de dados Excel, do pacote de programa Office. Com os dados coletados e sistematizados, foram analisadas as informações pertinentes aos objetivos da pesquisa. Os resultados e discussões são apresentados a seguir.

\section{RESULTADOS E DISCUSSÃO}

O dado mais relevante da presente pesquisa foi justamente observar quantas e quais bibliotecas oferecem o serviço de catálogo online, justamente por ser este um serviço importante para a divulgação dos acervos e para 0 compartilhamento e recuperação dos conteúdos informacionais mantidos pelas referidas instituições. Nesse sentido, foi observado que das 20 maiores cidades do estado do Paraná, apenas metade delas mantêm e divulgam os OPACs de suas bibliotecas públicas, enquanto a outra metade não disponibiliza ou não divulgam o serviço aos usuários. No quadro abaixo, é possível observar as 20 maiores cidades paranaenses no que se refere à adoção de catálogo online por suas bibliotecas públicas.

Quadro 2 - Cidades com e sem catálogo online

\begin{tabular}{|c|c|}
\hline Com catálogo online & Sem catálogo online \\
\hline Londrina & Curitiba \\
\hline Maringá* $^{*}$ & Foz do lguaçu \\
\hline Ponta Grossa* $^{*}$ & Colombo \\
\hline Cascavel $^{*}$ & Guarapuava \\
\hline
\end{tabular}




\begin{tabular}{|c|c|}
\hline São José dos Pinhais* $^{*}$ & Toledo \\
\hline Paranaguá* $^{*}$ & Apucarana \\
\hline Araucária & Pinhais \\
\hline Arapongas & Campo Largo \\
\hline Umuarama* $^{*}$ & Almirante Tamandaré \\
\hline Cambé $^{\text {Piraquara }}$ \\
\hline
\end{tabular}

Fonte: Dados da pesquisa

Dentre as dez cidades com OPACs, seis delas participam de um convênio com a Biblioteca Pública do Paraná, que é um órgão estadual. Nesse convênio os catálogos dessas bibliotecas municipais são acessados por meio de uma única página ${ }^{1}$, mantida pela Biblioteca Pública do Paraná, com o uso do software Pergamun, um dos softwares de gestão de bibliotecas mais utilizados no país.

Assim, as cidades de Maringá, Ponta Grossa, Cascavel, São José dos Pinhais, Paranaguá e Umuarama, disponibilizam acesso online aos catálogos de seus acervos utilizando o Pergamun, por meio da página da Biblioteca Pública do Paraná. O catálogo online oferece muitas das funcionalidades oferecidas pelo software Pergamun, tais como buscas simples e avançadas, uso de operadores booleanos, área do usuário, possibilidade de reserva e renovação de empréstimo, acesso mobile por smartphone e um canal de comunicação direto com a biblioteca escolhida pelo usuário. Os usuários dessas bibliotecas públicas também podem utilizar um filtro de pesquisa a fim de realizar a busca somente na biblioteca da cidade a qual for de seu interesse. Essa ação pode ser realizada como se mostra na figura a seguir.

Figura 1 - Filtro de bibliotecas públicas na Biblioteca Pública do Paraná

\footnotetext{
1 http://www.pergamum.bpp.pr.gov.br/
} 


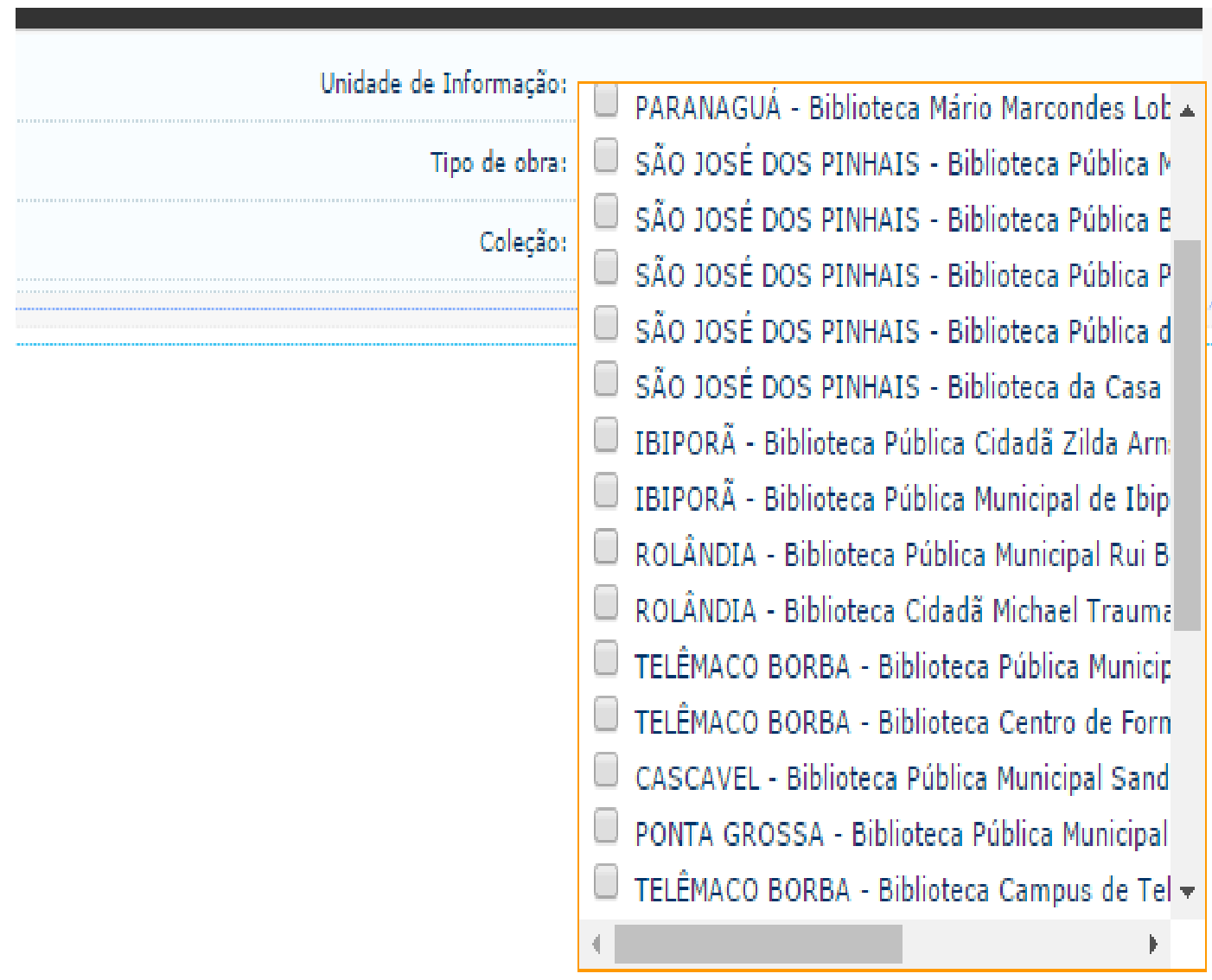

Fonte: (BIBLIOTECA PÚBLICA DO PARANÁ, 2019b).

Percebe-se que além das cidades mencionadas e que participaram desta pesquisa, outras cidades do estado do Paraná também participam do convênio com a Biblioteca Pública do Paraná, sendo elas: Ibiporã, Rolândia, Telêmaco Borba, Santa Helena, Tijucas do Sul, além da própria Biblioteca Pública do Paraná, que é o órgão que coordena o Sistema de Bibliotecas Públicas do Paraná, o qual as bibliotecas públicas dos municípios estaduais fazem parte.

O Sistema Estadual de Bibliotecas Públicas do Paraná é composto pelo conjunto de bibliotecas públicas do Estado, coordenado e administrado pela Biblioteca Pública do Paraná. A sua operacionalização cabe à Divisão de Extensão. O Sistema foi legitimado por decreto em 24 de julho de 1992. Atende prioritariamente as bibliotecas públicas através de convênios entre as partes, respeitando-se a autonomia dos municípios. Entre os objetivos deste Sistema de Bibliotecas Públicas, está a Implantação e constante aperfeiçoamento dos serviços de bibliotecas públicas, atendendo às necessidades da comunidade local. (BIBLIOTECA PÚBLICA DO PARANÁ, 2018a). 
Visto que a capital do estado, Curitiba, não dispõe de OPACs em suas bibliotecas públicas municipais, a cidade de Londrina destaca-se então por ser a maior cidade do estado do Paraná que conta com um catálogo online de acesso público mantido exclusivamente pelo sistema de bibliotecas do seu munícipio. O catálogo online oferece acesso aos registros bibliográficos dos acervos de sete bibliotecas públicas municipais, e para isso utiliza o software Sophia Biblioteca. O catálogo online pode ser acessado livremente pela internet ${ }^{2}$ desde março do ano de 2018. As facilidades disponibilizadas pelo catálogo online, com o uso do software Sophia, compreendem a busca simples e combinada, com o uso de operadores booleanos, a possibilidade da geração de levantamento bibliográfico, filtros por unidades de bibliotecas, acesso fácil a itens novos no acervo, além da possibilidade de avaliação de itens por parte dos usuários, favorecendo a interação entre leitores e bibliotecários.

Figura 2 - Catálogo online da Biblioteca Pública Municipal de Londrina

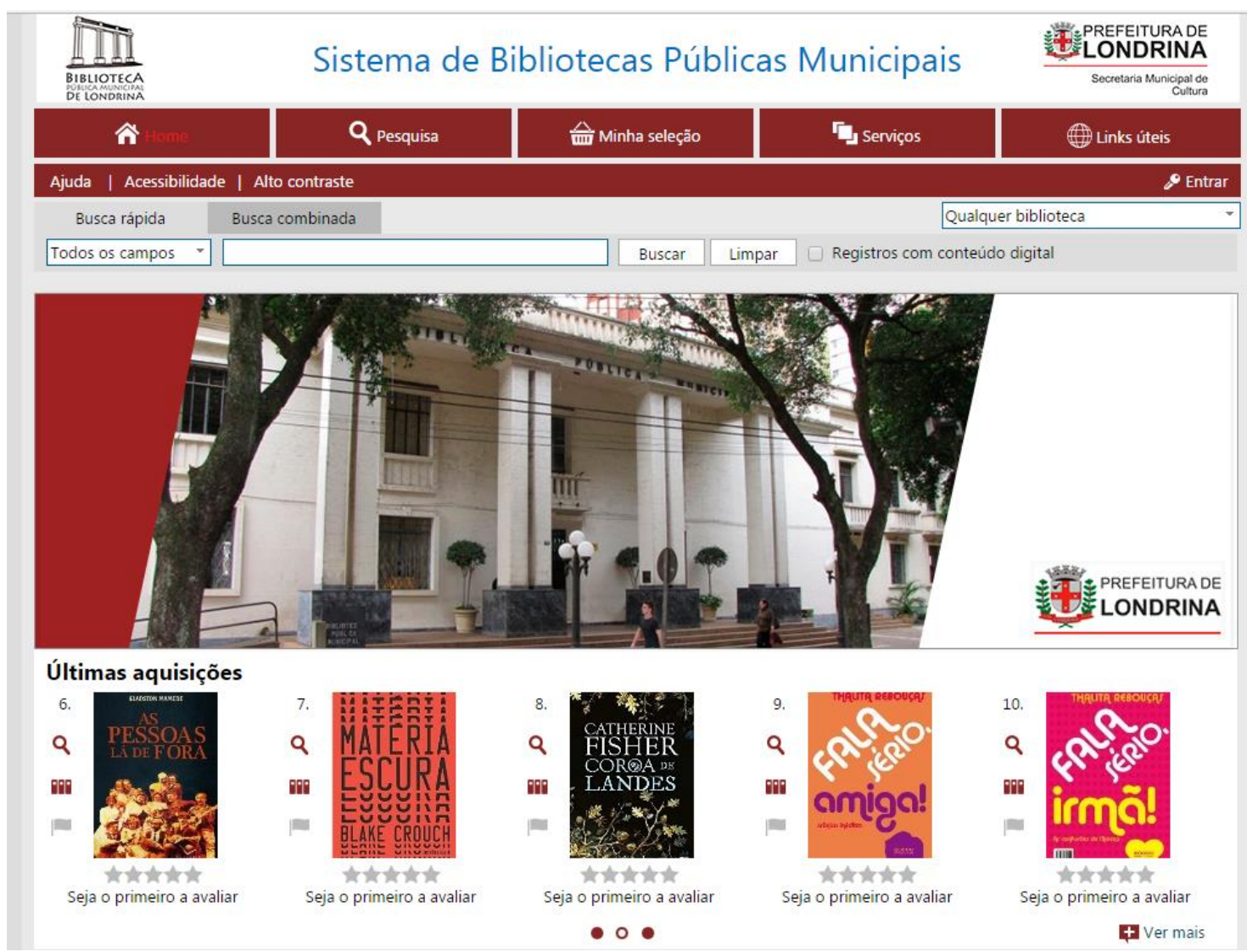

Fonte: (Sistema de Bibliotecas Públicas Municipais, 2019).

\footnotetext{
2 http://bibliotecas.londrina.pr.gov.br/
} 
As cidades de Arapongas $^{3}$ e Cambé 4 utilizam o software Biblivre para a gestão de seus acervos e também para disponibilizar o OPAC para os usuários. O Biblivre é um conhecido software para a gestão de bibliotecas com coleções pequenas ou médias. As funcionalidades oferecidas com seu uso, no que se refere ao catálogo online, no caso dessas cidades, não vão além das buscas simples e avançadas, respostas às perguntas frequentes e manuais de uso do catálogo online. A interface, simples e intuitiva, oferece uma experiência de busca bastante objetiva, porém sem maiores funcionalidades ou interações. A figura a seguir, ilustra como se apresenta o OPAC da Biblioteca Pública de Arapongas, exibindo o resultado de busca para o termo "Machado de Assis".

Figura 3 - Uso do Biblivre pela Biblioteca Pública de Arapongas

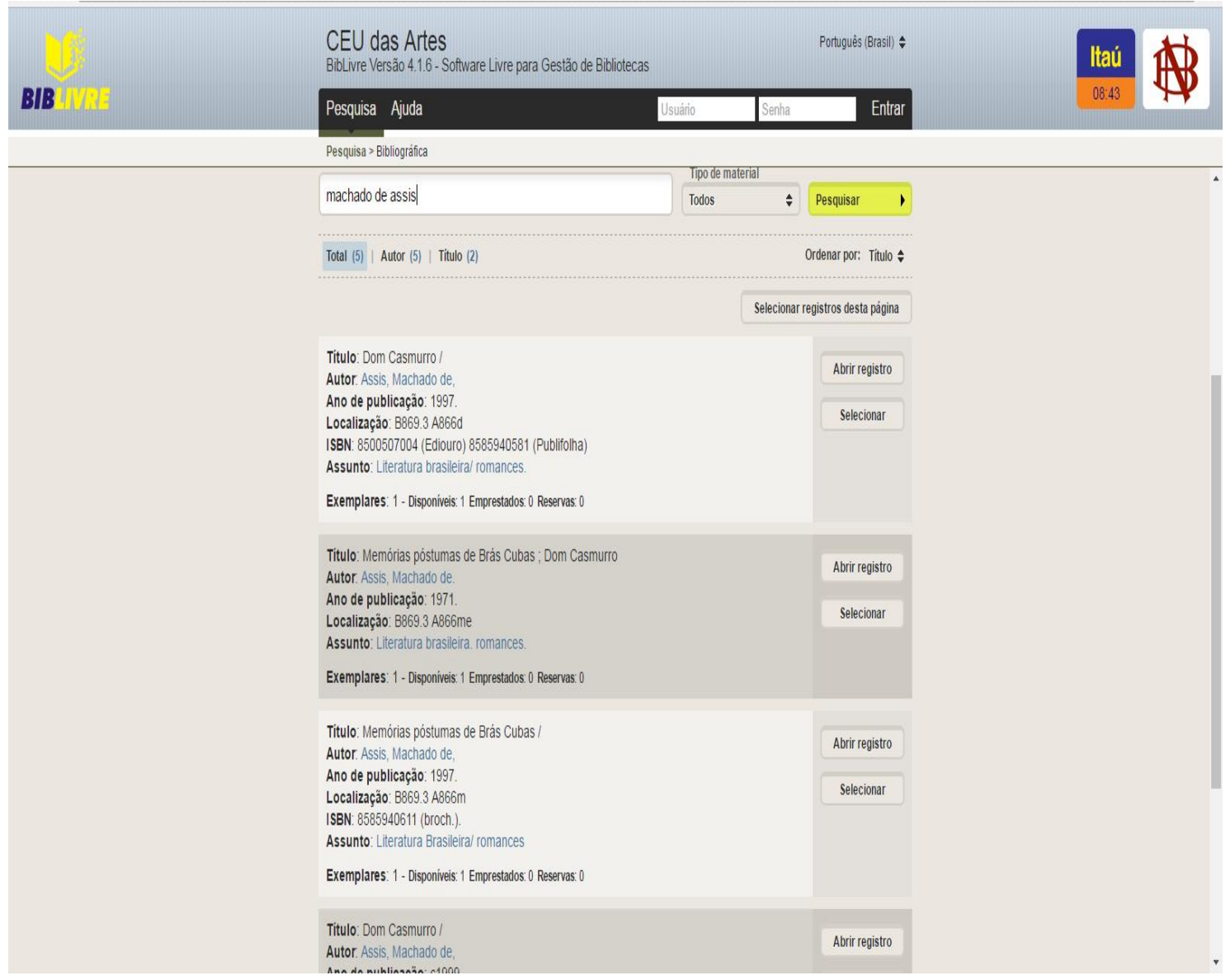

Fonte: (ACERVO LITERÁRIO DO MUNICÍPIO DE ARAPONGAS, 2019).

Outra cidade que se destaca em função de disponibilizar o serviço de

\footnotetext{
${ }^{3} \mathrm{http}: / /$ biblioteca.arapongas.pr.gov.br/

${ }^{4}$ http://biblioteca.cambe.pr.gov.br/
} 
OPAC de sua biblioteca pública municipal é Araucária, cidade com cerca de 140 mil habitantes, localizada na região metropolitana de Curitiba. (INSTITUTO BRASILEIRO DE GEOGRAFIA E ESTATÍSTICA, 2018).

A cidade de Araucária conta com o Sistema de Bibliotecas de Araucária, constituído por cinco bibliotecas, sendo que todas elas são atendidas pelo catálogo online que utiliza o software Pergamun 5 . Assim como as bibliotecas que participam do convênio com a Biblioteca Pública do Paraná, o catálogo online das bibliotecas públicas de Araucária utilizam as funcionalidades proporcionadas pelo Pergamun, tais como as buscas simples e avançadas, uso de operadores booleanos, área do usuário, possibilidade de reserva e renovação de empréstimo, acesso mobile por smartphone e um canal de comunicação direto com a biblioteca.

As cidades de Curitiba, Foz do Iguaçu, Colombo, Guarapuava, Toledo, Apucarana, Pinhais, Campo Largo, Almirante Tamandaré e Piraquara estão entre as 20 maiores cidade do estado do Paraná que não mantêm ou não divulgam a existência de um OPAC de suas bibliotecas públicas municipais.

Vale ressaltar que durante a coleta dos dados desta pesquisa, foram encontradas diversas informações a respeito das bibliotecas públicas municipais dessas cidades, no entanto, nenhuma das informações referia-se a existência de algum OPAC. Como já fora mencionado anteriormente, em alguns casos, foi necessária a comunicação via correio eletrônico, como no caso da capital do estado, Curitiba. Por meio da Fundação Cultural de Curitiba, foi informado que a cidade conta com dezenas de bibliotecas públicas municipais, denominadas, em sua maioria, como salas de leitura, no entanto nenhuma delas possui OPAC disponível aos usuários.

\section{CONSIDERAÇÕES FINAIS}

As tecnologias proporcionaram mudanças cruciais no contexto das bibliotecas públicas. Algumas dessas mudanças impactaram de maneira decisiva na forma de trabalho e interação da biblioteca, bibliotecários e usuários.

\footnotetext{
${ }^{5}$ http://biblioteca.araucaria.pr.gov.br/pergamum
} 
Uma dessas mudanças foi fortemente percebida nos catálogos das bibliotecas. Se antes os catálogos tinham funções bastante definidas, atualmente eles ganham, além das tradicionais funções, outras finalidades proporcionadas pelas diferentes tecnologias que podem ser a eles empregados. Entretanto, a adoção dos OPACs pode gerar custos substanciais às bibliotecas e infelizmente, muitas instituições não dispõem de custos financeiros para isso. Nesse contexto, bibliotecas como as universitárias e especializadas, notadamente com mais recursos, já utilizam OPACs há muitos anos, tendo assim mais familiaridade com as tecnologias proporcionadas pelos OPACs. Isso não se pode dizer, porém, em relação às bibliotecas públicas. Não é raro que essas bibliotecas sofram com falta de recursos financeiros, entre outros, o que acarreta, por exemplo, na impossibilidade em adotar softwares voltados a gestão e automação dessas bibliotecas.

Esses motivos podem justificar o que foi percebido nesta pesquisa: o uso de OPACs pelas bibliotecas públicas municipais, no caso das maiores cidades do estado do Paraná ainda é incipiente. Metade das bibliotecas públicas municipais das 20 maiores cidades do estado não dispõe de OPACs. Em relação as outras dez cidades que possuem OPACs, seis cidades oferecem acesso ao catálogo online de suas bibliotecas públicas municipais por meio de um convênio firmado entre essas bibliotecas e a Biblioteca Pública do Paraná, instituição vinculada ao governo estadual do Paraná e que coordena o Sistema Estadual de Bibliotecas Públicas do estado. Faz-se necessário refletir, entretanto, sobre os benefícios que convênios como esse podem trazer às bibliotecas públicas municipais. Embora o "compartilhamento" do OPAC possa trazer menos autonomia às bibliotecas participantes, essas bibliotecas podem ter nos convênios uma boa oportunidade para superar possíveis problemas de ordem financeira, de infraestrutura, de recursos humanos ou outros, e assim oferecer o serviço de OPAC aos usuários.

De toda maneira, bibliotecários e demais gestores públicos devem reunir esforços pela adoção dos OPACs nas bibliotecas públicas, sejam elas de grandes, médias ou pequenas cidades. É preciso compreender que os OPACs são ferramentas essenciais para, entre outras coisas, divulgar e maximizar 0 
acesso do público aos acervos das bibliotecas públicas, atraindo e possibilitando melhores meios de interação entre o público e as bibliotecas públicas, conferindo-Ihes maiores possibilidades dessas instituições desempenharem seu papel junto à sociedade.

\section{REFERÊNCIAS}

ACERVO LITERÁRIO DO MUNICÍPIO DE ARAPONGAS. Catálogo online. 2019. Disponível em: http://biblioteca.arapongas.pr.gov.br/. Acesso em: 12 maio 2019.

ARRUDA, S. M. de; CHAGAS, J. Glossário de biblioteconomia e ciências afim: português-inglês. Florianópolis: Cidade Futura, 2002.

BALBY, C. N. Estudos de uso de catálogos on-line (OPACs): revisão metodológica e aplicação da técnica de análise de log de transações a um OPAC de biblioteca. 2002. Tese (Doutorado em Ciências da Comunicação) Escola de Comunicações e Artes, Universidade de São Paulo. São Paulo, 2002.

\section{BIBLIOTECA PÚBLICA DO PARANÁ. Sistema Estadual de Bibliotecas}

Públicas. 2018a. Disponível em: http://www.bpp.pr.gov.br/Pagina/SistemaEstadual-de-Bibliotecas-Publicas. Acesso em: 10 fev. 2019a.

\section{BIBLIOTECA PÚBLICA DO PARANÁ. Guia de Bibliotecas Públicas}

Municipais do Paraná. 2019b. Disponível em:

https://www.bpp.pr.gov.br/Pagina/Guia-de-Bibliotecas-Publicas-Municipais-doParana. Acesso em: 15 fev. 2019b.

FIUZA, M. M. A catalogação bibliográfica até o advento das novas tecnologias. Revista da Escola de Biblioteconomia da UFMG, Belo Horizonte, v. 16, n. 1, p. 43-53, mar. 1987.

INSTITUTO BRASILEIRO DE GEOGRAFIA E ESTATÍSTICA. Brasil em síntese. 2018. Disponível em: https://cidades.ibge.gov.br/brasil/pr/panorama. Acesso em: 10 fev. 2019.

LEITÃO, P. J. O.; CALIXTO, J. A. O Catálogo 2.0 e os catálogos das bibliotecas públicas em Portugal. In: CONGRESSO NACIONAL DE BIBLIOTECÁRIOS, ARQUIVISTAS E DOCUMENTALISTAS, 11., 2012, Lisboa. Anais [...]. Lisboa: Associação Portuguesa de Bibliotecários, Arquivistas e Documentalistas, 2012. Disponível em:

https://www.bad.pt/publicacoes/index.php/congressosbad/article/view/322. Acesso em: 22 fev. 2019.

MEY, E. S. A. Catalogação e descrição bibliográfica. Brasília: ABDF, 1987. 
OLIVEIRA, C. C. V. de. A interação dos usuários da UFMG com o catálogo online do sistema Pergamum. 2008. 199 f. Dissertação (Mestrado em Ciência da Informação) - Universidade Federal de Minas Gerais, Escola de Ciência da Informação, Belo Horizonte, 2008.

SISTEMA DE BIBLIOTECAS PÚBLICAS MUNICIPAIS DE LONDRINA. Catálogo online. 2019. Disponível em: http://bibliotecas.londrina.pr.gov.br/. Acesso em: 10 maio 2019.

SOUZA, E. G. de. Os desafios da catalogação compartilhada: um estudo do OPAC Argonauta - UFF. In: ENCONTRO NACIONAL DE PESQUISA EM CIÊNCIA DA INFORMAÇÃO, 13., 2012. Rio de Janeiro. Anais [...]. Rio de Janeiro: IBICT, 2012.

SUAIDEN, E. J. A biblioteca pública no contexto da sociedade da informação. Ciência da Informação, Brasília, v. 29, n. 2, p. 52-60, maio/ago. 2000.

\title{
ONLINE CATALOG IN MUNICIPAL PUBLIC LIBRARIES IN THE STATE OF PARANÁ/BRAZIL
}

\begin{abstract}
Introduction: In the context of libraries, whether public or other types, the catalog has always played an important role in the tasks to locate, describe and catalog the information contents. Currently, with the wide possibilities of using Online Public Access Catalogs, or simply OPACs, libraries can use this tool, not only to retrieve, describe or inventory the collections, but also as an important channel of dissemination and communication with real users and potential of libraries. However, the context of Brazilian public libraries imposes barriers to the adoption of OPACs, since the costs of purchasing and maintaining software aimed at this purpose are not considered a priority for many of these institutions. Objective: This research aims to investigate the situation of municipal public libraries in the largest cities in the state of Paraná, regarding the adoption or not of OPACs, also observing, when appropriate, what software and functionalities exist in OPACs. Methodology: according to the objectives proposed for this work, it is an exploratory type of research with both a quantitative and qualitative approach. Results: half of the 20 cities surveyed, that is, 10 cities maintain OPACs, while in 10 other cities the tool was not perceived. Conclusions: The joint effort led by the Paraná Public Library, which is a state agency, stands out in a positive way, in terms of making it possible for some cities in Paraná to use the Pergamun software to provide online public access to their library catalogs. Just like Londrina, Araucária, Arapongas and Cambé, whose municipal public libraries use different software to manage their OPACs. However, the absence of OPACs in public libraries in 10 of the largest cities in Paraná, including the capital Curitiba, indicates that there is a long way to go in order to make the use of this important tool possible.
\end{abstract}

Descriptors: Online catalog. Online Public Access Catalogs. OPAC. Public Library.

\section{CATÁLOGO EN LÍNEA EN BIBLIOTECAS PÚBLICAS}




\title{
MUNICIPALES EN EL ESTADO DE PARANÁ / BRASIL
}

\begin{abstract}
RESUMEN
Introducción: en el contexto de las bibliotecas, sean públicas o de otro tipo, el catálogo siempre ha desempeñado un papel importante en las tareas de ubicar, describir y catalogar el contenido de la información. Actualmente, con las amplias posibilidades de usar catálogos de acceso público en línea, o simplemente OPAC, las bibliotecas pueden usar esta herramienta, no solo para recuperar, describir o inventariar las colecciones, sino también como un canal importante de difusión y comunicación con usuarios reales y el potencial de bibliotecas Sin embargo, el contexto de las bibliotecas públicas brasileñas impone barreras para la adopción de OPAC, ya que los costos de compra y mantenimiento de software destinados a este propósito no se consideran una prioridad para muchas de estas instituciones. Objetivo: Tiene como objetivo investigar la situación de las bibliotecas públicas municipales en las ciudades más grandes del estado de Paraná, con respecto a la adopción o no de los OPAC, también observando, cuando sea apropiado, qué software y funcionalidades existen en los OPAC. Metodología: de acuerdo con los objetivos propuestos para este trabajo, es un tipo de investigación exploratoria con enfoque tanto cuantitativo como cualitativo. Resultados: la mitad de las 20 ciudades encuestadas, es decir, 10 ciudades mantienen OPAC, mientras que en otras 10 ciudades no se percibió la herramienta. Conclusiones: El esfuerzo conjunto liderado por la Biblioteca Pública de Paraná, que es una agencia estatal, se destaca de manera positiva, en términos de hacer posible que algunas ciudades de Paraná utilicen el software Pergamun para proporcionar acceso público en línea a los catálogos de sus bibliotecas. Al igual que Londrina, Araucária, Arapongas y Cambé, cuyas bibliotecas públicas municipales utilizan diferentes softwares para administrar sus OPAC. Sin embargo, la ausencia de OPAC en las bibliotecas públicas de 10 de las ciudades más grandes de Paraná, incluida la capital Curitiba, indica que hay un largo camino por recorrer para hacer posible el uso de esta importante herramienta.
\end{abstract}

Descriptores: Catálogo en línea. Catálogos de acceso público en línea. OPAC. Biblioteca pública.

Recebido em: 19.10.2019

Aceito em: 07.05.2020 